\section{International Scientific Journal Theoretical \& Applied Science}

p-ISSN: 2308-4944 (print) ｅ-ISSN: 2409-0085 (online)

Year: $2016 \quad$ Issue: 9 Volume: 41

Published: $30.09 .2016 \quad$ http://T-Science.org
Shirin Hakimovna Alpanova

Assistant of the chair of

"Uzbek linguistics" of

Andizhan State University,

Andizhan, Uzbekistan

shirin.adu@mail.ru

SECTION 29. Literature. Folklore. Translation

Studies.

\title{
PSYCHOLOGIC ANALYSES OF THE NOTION OF ASYMMETRY IN THE PROCESS OF COMMUNICATION
}

Abstract: In this article the psychologic changes in the process of speech are discussed. The influence of psychologic and affect states in the process of speech is analyzed on the bases of the texts taken from fiction.

Key words: mentality, motivation, thought, inner speech, loud speech, text.

Language: English

Citation: Alpanova SH (2016) PSYCHOLOGIC ANALYSES OF THE NOTION OF ASYMMETRY IN THE PROCESS OF COMMUNICATION. ISJ Theoretical \& Applied Science, 09 (41): 45-48.

Soi: http://s-o-i.org/1.1/TAS-09-41-6 Doi: crossef http://dx.doi.org/10.15863/TAS.2016.09.41.6

Psycholinguistics in the Uzbek linguistics is considered a relatively new interdisciplinary science. Thanks to its innovative approach it has established itself as a scientific space of the national psychology, physiology and linguistics. Considering the production of speech, psycholinguistics describes how the language system and the rules for constructing speech enable a person to express his thoughts. Describing the process of speech perception, psycholinguistics analyzes not only the process itself, but also the result of understanding human speech. Psycholinguistics describes how it reflects our involvement in joint activities interlocutor. When we learn the relation between the language and thought, how the impact on the human mind through language, we understand why language is a powerful tool for the control of human behavior. As we know, the object of psycholinguistics is a collection of individual objects which it studies. The subject of science is an abstract system of objects or some system of abstract objects. The subject of Psycholinguistics is other than that of linguistics. Psycholinguistics interested in the process of functioning of the sign system, namely, the process of creation and perception of sign language by people. Thus, psycholinguistics on the project coincides with linguistics, and on the subject varies with it. Psycholinguistics deals with the processes of encoding and decoding, as they relate to the state of information with the state of the participants of communication. Here it is supposed that the processes of speech relates not to a language system, but to a man, with his mentality.
Psycholinguistics has three subject areas:

a) the production of speech;

b) the perception of speech;

c) the formation of speech.

And in each case it is assumed that psycholinguistics draws its attention to those sides of these types of speech activity, which are due to the language system. In fact the intercourse is considered not as a simple way of sending information from one individual to another, but as a process of internal regulation of society itself. Perceptions of speech are considered in the context of in psycholinguistics. Every reader will understand the text in its own way and it is called the interpretation of the text. In such interpretations the special role is played by cultural and national characteristics of the subject. Psycholinguistics studies the text, how the text exists in the minds of those who perceive it. That's why the idea of individuals on the language system bear the imprint of the personal experience. According to psycholinguistic concepts of the human speech organization is not a passive repository of information about language. This is dynamic (moving) functional system. Receiving new information a person remakes it. Language reflects the culture of the people. Language is the main activity not only the human, but also the national spirit - the spirit of the people. Specially studied the psycholinguistic characteristics of speech under emotional stress, where the correct orientation is difficult or completely broken. In such cases the following psycholinguistic signs of emotion reveal: the average length of the interval between the speech 
pauses is less; the average duration of a pause is longer; the ratio of the durations of pauses to the duration of the speech sound better; the number of false starts, paraphrases, semantically irrelevant repetitions, grammar disagreements, logically and grammatically incomplete sentences, functional inversions, speech stereotypes are more; volume fluctuation (more noticeable); the percentage of statements with a clear positive or negative connotation are (much more); Semantic fragmentation or meaninglessness, usually while maintaining the integrity of the grammatical phrase. The phonetic monotony or patients reinforce the tone in the subsidiary, secondary parts of the sentence and muffles it in the main, the semantic part. Repetition of words pronounced by the interlocutor and the senseless shouting the same words, the same phrases as can be seen. As it is seen the symptoms are very different, reflecting the diversity of forms of schizophrenia The so-called Korsakov psychosis: a sharp memory disorder, reflected in speech (eg, in paraph - one word "pops up" instead of another) occurs in organic brain lesions, or as a consequence of chronic alcoholism. The so-called Pick's disease or Alzheimer's: a noticeable speech stereotype - phrases are composed of the same expressions and are pronounced with the same tone, and the same facial expressions and gestures. The study of the mechanisms of development of language and speech ability, Rece perception and speech production process takes place through research relationships with speech consciousness and sub consciousness, emotions and intellect. Moreover, all mental processes without exception, both cognitive and emotional, not simply matched with speech, but were considered as indispensable components of speech. We have also considered speech in the context of its relations with the mental qualities and the state of the individual. On a materials taken from the Uzbek literature there was traced a link between cognitive (perception, attention, memory, thinking, imagination) aspect of speech, psychodynamic (motive, affective, emotional) features and a communicative aspect. As a rule studies on such issues and also the development of language and speech ability, perception and speech production in adults were the subject of investigation.

The aspiration for studying the formation of speech and the factor of a person who perceives it has a long history in the Uzbek linguistics. The person who is producing words picks up them like a jeweler as Navoi stated "in the form a bunch of pearls (words)" [1.77-8.168]

According to Modern linguistics the linguistic structures (phoneme, morpheme, lexeme and forms) are general and they appear in speech in the form of a sound, letter, syllable, suffix, word, word combination, sentence and a text. [2.10-10.84]
That's why psycholinguists analyzing these characteristic features of speech are general phenomena and the result of a person's natural speech activity has achieved much success in solving the problems of text analyses.

Psycholinguists studies the speech as the method of expressing the reality. And at the same time speech being the main method of exchanging and keeping information is also the reflection of culture, a period of history and a person's spiritual world. And this was the reason why there appeared different definitions given to this phenomena by the linguists. The definition "text doesn't exist out of the process of its creation" given by A.A.Leontiev demands to give a special attention to above mentioned processes in psycholinguistics and study them in the semantic, psychologic, pragmatic, cognitive aspects.

The approach to the text as the result of speech activity is the characteristic feature of psycholinguistics. During the speech intercourse one of the partners tries to influence on the other and change his/her motions and emotional state. In other words during the conversation one of the partners by actions without a word or by words tries to influence on his/her spiritual state and speech. The changing of spiritual state follows the changing relations of a person to interlocutor and it sometimes brings to changing relations. And that means it is important to understand the terms of relations, because speech as the bases of relations has influensive strength.

At first it is important to select the language units according to the terms of speech contacts. And then the recipient should receive the speaker's idea according to his own needs. Such approach to the problems of speech contacts planed two directions of text analyses. The first direction studies the process of text formation and the second how the recipient understands the meaning of the text.

Two stages of speech formation first stressed out by A.S.Vigotskey who said that "the movement in the program of thought speech begins with motive and progresses in thought first in the form of a word in inner speech and then in loud speech". [4.43-9.21] Here it is important to stress one movement. We think this theory is characteristic for healthy people but in mentally sick people this inner stage of forming words is absent. In such people it appears in loud speech unwillingly. According to A.S.Vigotskey the first is a motivating stage, which precedes the stage of formation of thought. Here we'd like to present some examples taken from fiction to prove this idea.

"Good received our daughter's prays at dawns, I feel better, don't wake her up at dawns now". She closed her eyes and didn't open then. At dawn she died. Father wanted to take his little girl to another room from her mother's dead body and at this moment she didn't open her eyes and prayed: "Oh 
God bless my mother and give treatment to her illness. [5.290] In this passage, taken from famous story by Abdulla Qahhor a little girl repeats the words sleeping and without knowing that her mother has already dead. Here the reality hasn't found its reflection in her mind yet. The aim, thinking, word selecting processes didn't exist here in interior speech but reflects in loud speech. The little girl's words appear here in the form of conditional reflex, because she was made to pray at dawns every day for the sake of her sick mother. This often happens in young children's speech and they don't analyze the words weather they are positive or negative. We think that interior stage is absent here.

Here is another example taken from the novel of "The past days" (O'tkan kunlar) by A.Qodiriy.

"... There was somebody coming.

"Who is this?"

"It 's me, Kumush..."

Otabek recognized her, that was crazy Zaynab.

"Go away!"

"It's me, Kumush" said Zaynab.

Zaynab become crazy because of her love to Otabek and even then she wanted to be "Kumush" for her beloved person. Because of this love she goes mad and then became murderer. And for this unhappy woman the only word "Kumush" was the key for happiness and love. But miracle wasn't happened, this magic word had been lost for ever and then looking back again and again Zaynab went away" [6.385]

This example proves that mentally sick persons usually repeat the words because of which they become mad. They don't really recognize the meaning of the words which they repeat unconsciously. Here is one more example. "Qurbonbibi always talks to herself and if somebody approaches to her, she praised Zebi and said how she played dutor, how she sang a song, sew scull caps and she also praised her beautiful figure, eyes and brows. And then all of a sudden she begins to ask everybody saying "Where is Zebi? Where is my dolling Zebi? Then begins to cry".

In this both above mentioned examples there are no thought and motive processes according to speech situation. That is why such affect states should be studied from the theoretical point of view.

Let's analyze one more example.
“... Mother, I'm not upset of him. My life and my youth are spent waiting for him at night", -she said. And at this moment the door of the room opened and drunk Qodirjon entered the room. Seeing him they both said "there, he has come". But instead answering them Qodirjon asked "Where is, where is my Anna, where is my dolling Anna? And then fell down [8.285]

There is saying among the people "A drunken person says the truth". And that's true because a person becoming drunk tells the words which he would not say them when they are conscious. But the words, hidden under thought usually come out or realized in loud speech when a person is under hypnotic state or being drunk. Having analyzed above mentioned psychologic conditions we differentiate three types of speech formation processes.

The first type is characteristic for mentally healthy people's speech, the second type is characteristic for formation of speech in affect conditions. And the third type can be seen in the speech of both types of people: mentally healthy and mentally sick. In the first type the realization of speech happens in the following way.

I. Inner speech: 1. Aim. 2. Thought. 3. Inner programming.

II. Loud (enter) speech.

The second type is characterized with missing all processes concerning to the formation of inner speech in affective states. It has the model: inner speech- 0. (zero) Loud speech doesn't always correspond to the real speech situation but it is a speech corresponds to psychological state of a person. In the strong state of stress the speech may loose its activity and may not work. That's why the following model is characteristic for the second type, i.d. for loud speech in such cases:

I. Inner speech -0

II. Loud speech- 0

Here is an example for it: "... after that she burst out into tears" [7.265]

In such situations mimes play the main role in the process of communication. That's why it needs a special psycholinguistic analyzes correspondingly to a new direction of scientific researches.

\section{References:}

1. Nurmanov A (2002) History of Uzbek linguistics. -Tashkent 2002.
2. Shahobiddinova S (2002) General and private dialectics and it's images in Uzbek morphology. -Tashkent 2002. 


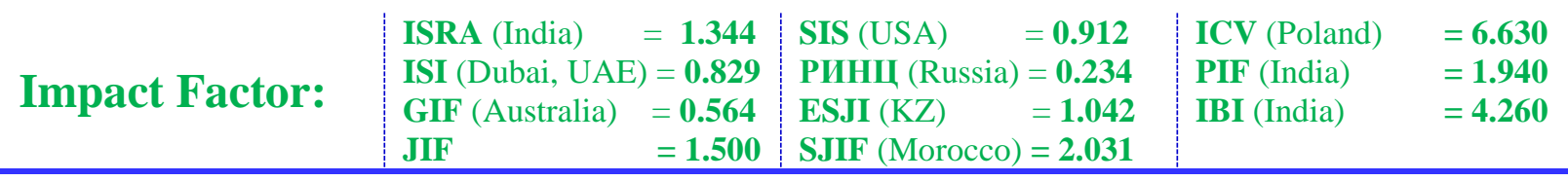

3. Leontief AA (1960) Psycholinguistic unit and generation the speech statement.

Moscow, 1960.

4. Vigotskey AS (1956) The elected psychological researches. Moscow, 1956.

5. Kahhor A. Selected works Volume 5.Tashkent.,1987.

6. Qodiriy A (1974) "The past days". Tashkent, 1974.

7. Chulpon A (1994) Selected works Volume 3 and 2.-Tashkent, 1994.
8. Сорокин ЮА Психолингвистические

(1985) изучения текста.М., 1985.

9. Safarov SH (2006) Kognitiv tilshunoslik. Jizzax, 2006.

10. Mahmudov N (2014) So'z ma'no taraqqiyotida ziddiyat. -Tashkent, 2014 